Revista lus et Praxis, Año 21, No 2, 2015, pp. 415 - 438

ISSN 0717 - 2877

Universidad de Talca - Facultad de Ciencias Jurídicas y Sociales

La medida cautelar innominada y anticipatoria en el proceso de responsabilidad

del Estado por desplazamiento forzado en Colombia

Diego Armando Yáñez Meza

Trabajo recibido el 20 de octubre del 2014 y aprobado el 20 de marzo del 2015

\title{
La medida cautelar innominada y anticipatoria en el proceso de responsabilidad del Estado por desplazamiento forzado en Colombia*
}

\author{
THE INNOMINATE PRECAUTIONARY MEASURE AND ANTICIPATORY IN THE PROCESS \\ OF STATE RESPONSIBILITY BECAUSE OF FORCED DISPLACEMENT IN COLOMBIA
}

\section{Diego Armando Yáñez Meza**}

... la garantía cautelar está destinada, más que a hacer justicia, a dar tiempo a la justicia de cumplir eficazmente su obra... ...es la sombra que precede al cuerpo...

\section{RESUMEN}

En la actualidad colombiana la pretensión cautelar suscita múltiples desafíos en torno a la prometida protección efectiva de los derechos. Cierto sector de la doctrina proclama sus virtudes frente a la congestión judicial y el retardo irrazonable de los procesos judiciales; otros guardan serias reservas frente al poder del juez y la indefinición de límites claros frente al alcance de la eventual orden cautelar. En este nuevo escenario de debate académico y en observancia de un problema propio del contexto social colombiano en las víctimas del desplazamiento forzado, se aborda el examen descriptivo, analítico, correlacional y propositivo, en aras de establecer

\footnotetext{
* El presente artículo de investigación e innovación hace parte del proyecto de investigación "La medida cautelar en el proceso de responsabilidad extracontractual del Estado por desplazamiento forzado en Colombia" desarrollado por el Grupo de Investigación en Derecho Público y Semillero de Investigación en Derecho Administrativo "Louis Antoine Macarel" de la Universidad Libre Seccional Cúcuta, Colombia, adscrito a la línea de investigación "Conocimiento, innovación y desarrollo sostenible regional", sublínea "Justicia, derecho procesal y sistema penal acusatorio". El autor agradece la contribución al proceso investigativo como Semilleros de investigación a los estudiantes BAYRON OMAR Albarracín Monsalve, Ana Milena Chaustre González, Paola lópez Guerrero, María Victoria Carvajalino Clavijo, Paola Andrea Cárdenas Andrade, Andrea Esther Rincón Jaimes, Daniela laguado Salazar, Daniela Ramírez López, Camilo Andrés Prada Álvarez; así mismo, manifiesta la contribución al proceso investigativo como Auxiliar de investigación del estudiante Jeferson Arley Castellanos Castellanos.

** Director Grupo de Investigación en Derecho Público y del Semillero de Investigación en Derecho Administrativo "Louis Antoine Macarel" de la Universidad Libre Seccional Cúcuta. Docente en la cátedra Derecho Administrativo General y Colombiano \& Responsabilidad Civil. Abogado, Universidad Libre Seccional Cúcuta. Especialista en Derecho Público, Universidad Externado de Colombia. Magíster en Derecho Administrativo (Investigativa), Universidad Externado de Colombia. Magíster (C) en Derecho Procesal Contemporáneo (Investigativa), Universidad de Medellín. Doctorando (C) en Derecho Procesal Contemporáneo, Universidad de Medellín. Autor de distintos libros y artículos de investigación. Correo electrónico: diego.yanez@unilibrecucuta.edu.co; diegoymezabogado@gmail.com.
}

${ }^{1}$ Calamandrei (1962), p. 421. 
la procedencia de una orden cautelar en el contexto de los procesos de responsabilidad -los cuales se caracterizan por su morosidad, etc.-, que garantice el derecho a la reparación en su dimensión compensatoria -pago cautelar del perjuicio moral y por alteración de las condiciones de existencia- y sobre el derecho de propiedad en el otorgamiento de condiciones de seguridad en el sitio de expulsión tan pronto ocurren los actos que causan el éxodo que constriñe al traslado involuntario.

ABSTRACT

This document provides a succinct description of the many challenges that arise in the current Colombian proceeding regulation regarding the injunction and the effective protection of the rights of individuals; while some indoctrinators expose the advantages that this regulation presents for the decongestion of court offices and the course of the processes within a reasonable time, others point out the problems that may occur in relation to the power of the judge and the inadequate definition of the limits of that power and the scope of the injunction. In this new scenario, the focus of this paper contains a descriptive, analytic and correlational examination in the Colombian social context of processes involving victims of forced displacement, in order to establish the rationality of a measure of caution into processes responsibility which are characterized by their delinquency, among other problems, proposing mechanisms to ensure effectiveness and guarantee the right to reparation in its compensatory dimension; payment of pecuniary damage and altering conditions of existence, and the right of property in the granting of security conditions in the site as soon removal acts that cause displacement and constrain the displacement occurs.

\section{PALABRAS CLAVE}

Medida cautelar innominada, Responsabilidad del Estado, Desplazamiento forzado, Derecho a la reparación, Derecho de propiedad, Reforma procesal administrativa

\section{KEY WORDS}

Innominate injunction, State responsibility, Forced displacement, The right to redress, Right to property, Administrative procedure reform

\section{Introducción}

La situación de las personas víctimas del desplazamiento forzado en Colombia descubrió en la jurisprudencia de la Corte Constitucional la existencia de un Estado de Cosas Inconstitucional ${ }^{2}$ que, en vigencia de la Constitución Política de 1991, precisa que los hechos en los que se desenvuelve la vida de estas personas son contrarios a la Constitución. Este fenómeno calificado en doctrina como "el flagelo más ignominioso, que atenta contra la convivencia pacífica del tejido social colombiano"3 y que al mes de septiembre del año 2014 revela que en el país existen cinco millones ochocientos noventa y siete mil cuatrocientos treinta y cinco víctimas por esta causa ${ }^{4}$, enfrenta al Estado a uno

${ }^{2}$ Corte Constitucional. Sentencia de Tutela 025. 22 de enero del 2004.

3 Álvarez (2008), p. 13.

${ }^{4}$ Unidad para la atención y reparación integral a las víctimas (2014). 
de los problemas más complejos ${ }^{5}$ al verse comprometidos los derechos sobre sujetos que ostentan una especial protección constitucional y cuya condición debe ser atendida desde i) la perspectiva de un enfoque de asistencia social y ii) de un enfoque de derechos -en el cual se ubica el derecho a la reparación del daño-.

Esa relación numerosa de derechos fundamentales comprometidos en el iter de los hechos que configuran el desplazamiento forzado ${ }^{6}$, frente al derecho a la reparación integral del daño causado y desde una perspectiva judicial de la reparación ${ }^{7}$, encuentra en el ordenamiento jurídico y en el derecho contencioso administrativo como procesos adecuados para pretender la garantía efectiva del derecho en comento a los medios de control de reparación directa y de grupo ${ }^{8}$. Conforme a la línea jurisprudencial existente en las providencias del Consejo de Estado en Colombia ${ }^{9}$ este es un juicio de responsabilidad que se construye dentro del sistema subjetivo de responsabilidad del Estado, en la falla en la prestación del servicio de seguridad y protección a cargo de, principalmente, La Nación-Ministerio de Defensa-Ejército Nacional y Policía Nacional.

En los procesos contenciosos de responsabilidad patrimonial y administrativa referidos en la línea jurisprudencial analizada ${ }^{10}$ no existe antecedente que permita evidenciar la solicitud, decreto o práctica de una medida cautelar en las pretensiones de responsabilidad del Estado desde perspectiva alguna; ciertamente, bajo la vigencia del Código Contencioso Administrativo -en adelante CCA - al estar limitado el derecho procesal administrativo a la exclusividad de la medida de suspensión provisional de los actos administrativos ${ }^{11}$, el juez y el litigante en Colombia no estaban habilitados para innovar en el asunto. Podría afirmarse que en esta materia la creatividad de quien pedía justicia -el litigante- y de quien la otorgaba -el juez administrativo- estaba condenada y el derecho a la reparación sacrificado en el tiempo. Esta fue y es una realidad

\footnotetext{
${ }^{5}$ Alpargatero (2011), pp. 1-118.

${ }^{6}$ YÁÑ̃ez (2013 a), p. 216.

7 PeÑA (2011), p. 12.

${ }^{8}$ Consúltese al respecto: Decreto Ley № 01, de 1984, art. 86; Ley № 1437, de 2011, art. 140; Constitución Política de Colombia, de 1991, art. 88, inciso $2^{\circ}$.

9 YÁÑEZ (2013 b), pp. 13-46.

${ }^{10}$ La línea jurisprudencial existente en las decisiones del Consejo de Estado colombiano y que en la presente investigación se emplea, se construye desde el año 2002 hasta el año 2010, fechas en las cuales se emite la primera y última decisión en la materia -sentencia fundadora y arquimédica-. Consúltese frente a la metodología de análisis de jurisprudencia: López (2006), pp. 1-366. Para el período reseñado aún no había entrado en vigencia en Colombia el Código de Procedimiento Administrativo y de lo Contencioso Administrativo: Ley 1437, de 2011; para la época indicada se encontraba en vigencia el Código Contencioso Administrativo: Decreto Ley № 01, de 1984.

11 Consúltese al respecto: Decreto Ley № 01, de 1984, arts. 152-159.
} 
de la práctica judicial en Colombia y una perspectiva teórica del problema jurídico que se plantea.

Debe señalarse que no existen estudios realizados por la doctrina colombiana y la jurisprudencia contencioso-administrativa a partir de las decisiones del máximo tribunal contencioso administrativo, respecto al problema que en esta investigación se plantea.

Desde este enfoque se navega a hombros de gigantes junto a la más autorizada doctrina en la teoría tradicional de las medidas cautelares ${ }^{12}$, presentando un nuevo enfoque en su aplicación a partir de la tragedia de las víctimas de desplazamiento forzado en Colombia y desde el ámbito del derecho de la responsabilidad y la reparación.

\section{Planteamiento del problema}

El juicio de responsabilidad extracontractual del Estado por desplazamiento forzado se define, dada la magnitud actual de víctimas, como uno de los desafíos más complejos al cumplimiento de los fines esenciales del Estado precisados en la Constitución Política de $1991^{13}$. Sin lugar a dudas, frente al daño causado el Estado incumple contenidos obligacionales de carácter constitucional, lo cual, junto a otros elementos, genera responsabilidad constitucional ante la lesión -amenaza, vulneración o daño- de derechos fundamentales con el consecuente deber de reparación integral ${ }^{14}$. En este contexto, la presente investigación pretende -en el ejercicio de las típicas, en otrora acciones de reparación definidas por el legislador en Colombia en el medio de control de reparación directa y de grupo- establecer la procedencia de la acción cautelar anticipatoria e innominada frente a la protección del derecho a la reparación en su dimensión compensatoria y en la garantía efectiva del derecho de propiedad en los procesos donde se discute la responsabilidad del Estado por desplazamiento forzado, una responsabilidad que es de naturaleza extracontractual ${ }^{15}$.

La singularidad en relación al mentado proceso de responsabilidad se encuentra en que a pesar de la existencia de más de cincuenta años de conflicto armado interno, el Consejo de Estado colombiano tan solo ha emitido seis decisiones frente al problema jurídico de responsabilidad patrimonial y administrativa del Estado por desplazamiento forzado y, en consecuencia, solo un

\footnotetext{
12 Marinoni (2010), Balcázar (2010), Fábrega (1998), Calamandrei (2005).

13 Constitución Política de Colombia, de 1991, art. 2.

14 Ley Nº 446, de 1998, art. 16. "Valoración de daños. Dentro de cualquier proceso que se surta ante la Administración de Justicia, la valoración de daños irrogados a las personas y a las cosas, atenderá los principios de reparación integral y equidad y observará los criterios técnicos actuariales".

15 Consúltese al respecto: SARmiento (2013), pp. 217-247.
} 
diminuto número de colombianos ha encontrado en la justicia la protección de su derecho a la reparación. De este conjunto de providencias cinco corresponden al medio de control de grupo y una al de reparación directa ${ }^{16}$; en ninguno de estos procesos y en toda la historia de la jurisdicción contencioso-administrativa en Colombia se han adoptado medidas cautelares de ninguna naturaleza en esta pretensión.

De otra parte, se evidencia desde la responsabilidad internacional de los Estados por desplazamiento forzado en las decisiones de la Corte Interamericana de Derechos Humanos y la Comisión Interamericana de Derechos Humanos, que este sistema ha permitido la adopción de medidas provisionales y cautelares para i) la protección de la vida e integridad personal y ii) frente a la garantía de las condiciones de seguridad necesarias para que se respete el derecho a la libre circulación de las personas y de aquellos que se vieron forzados a desplazarse a otro lugar para que puedan regresar a sus hogares si lo desean ${ }^{17}$. En este escenario, el juez internacional ha asumido en la lógica de la acción cautelar un papel más activo que el juez colombiano frente a la protección cautelar de ciertos derechos de la población desplazada.

\section{Hipótesis}

Consideramos que la inactividad y el contraste existente entre el papel del juez en Colombia y el juez internacional ${ }^{18}$, con la reciente expedición del Código General del Proceso ${ }^{19}$-en adelante CGP- y el Código de Procedimiento Administrativo y de lo Contencioso Administrativo ${ }^{20}$-en adelante CPACA- debe cambiar; en virtud de estas novedades legislativas procesales ahora el juez en Colombia cuenta con la efectiva posibilidad de decretar medidas cautelares preventivas, conservativas, anticipativas, de suspensión, de urgencia y todas aquellas posibles dentro de la concepción de la medida cautelar innominada, la cual encuentra como límite la imaginación del litigante y la ponderación del juez.

Al transformarse el orden jurídico vigente la práctica judicial no debe seguir la ideología del pasado, existiendo un deber de aplicación que evite que las nuevas instituciones sean meramente nominales. Ante este nuevo contexto y la tragedia de las víctimas de una de las violaciones más flagrantes a los derechos

\footnotetext{
16 Yáñez (2013 b), pp. 13-46.

17 Corte Interamericana de Derechos Humanos. Resolución Caso Pueblo Indígena Kankuamo. Julio 5 del 2004.

${ }^{18}$ Consúltese al respecto: YÁÑEZ (2012), pp. 7-34.

19 Ley No 1564, de 2012.

20 Ley $\mathrm{N}^{0} 1437$, de 2011.
} 
humanos en Colombia - desplazamiento forzado- la nueva acción cautelar del derecho administrativo y general del proceso debe responderle a la víctima, en particular sobre dos variables angulares de su condición: el derecho a la reparación y el derecho de propiedad, de esta manera se identifican las necesidades que justifican la formulación de la cuestión de investigación.

\section{Problema jurídico}

¿Cuáles son los presupuestos que harían procedente la acción cautelar innominada y anticipatoria en Colombia, frente a la protección del derecho a la reparación en su dimensión compensatoria y en la garantía efectiva del derecho de propiedad en los procesos de responsabilidad del Estado por desplazamiento forzado?

La cuestión formulada encuentra soporte, de una parte, en el reconocimiento de la complejidad y la diversidad de funciones que la actividad jurisdiccional disciplina y la alternancia que depende de lo que el juez pueda realizar más allá de lo legislado y, de otra, en el mandato de creatividad del abogado que debe solicitar desde la demanda innovaciones de pretensión que no se muestran en el clásico conjunto de lo "material" y lo "procesal", dado que el proceso y la controversia judicial ya no debe concebirse como una lucha entre las partes ${ }^{21}$, donde el derecho se define, en ocasiones, por la diligencia o descuido del abogado, sino como el verdadero reflejo de una necesidad de derecho sustancial que involucra una tragedia en torno a intereses económicos, una vida en condiciones dignas y de garantía de la libertad.

Debe precisarse que el objeto de la investigación no aborda el estudio de la procedencia de la medida cautelar desde los procesos creados a partir de la perspectiva política de la reparación, como lo son aquellos diseñados en virtud de la Ley de Víctimas y Restitución de Tierras ${ }^{22}$ y sus decretos reglamentarios, se reitera que el objeto se delimita en la perspectiva judicial de la reparación, donde se define la responsabilidad del Estado y no donde actúa bajo criterios de solidaridad, dignidad humana, etc.

\section{Esquema de resolución}

El problema jurídico planteado se resolverá en atención al siguiente orden: se examinará i) la problemática del desplazamiento forzado de personas en Colombia ii) el juicio de responsabilidad del Estado por desplazamiento forzado en la jurisprudencia del Consejo de Estado colombiano, iii) las medidas cautelares en el juicio de responsabilidad del Estado por desplazamiento

21 GozAín (2013), pp. 41-57.

22 Ley $N^{\circ} 1448$, de 2011. 
forzado en Colombia, iv) las medidas cautelares y provisionales en el juicio de responsabilidad internacional de los Estados por desplazamiento forzado, v) la necesidad y suficiencia de la medida cautelar innominada-conservativa en la protección del derecho fundamental a la propiedad y vi) la necesidad y suficiencia de la medida cautelar innominada-anticipativa frente a la pretensión económica en la reparación del perjuicio moral y por alteración de las condiciones de existencia, vii) la orden cautelar en el pago de sumas de dinero derivadas del incumplimiento total, parcial o tardío de contenidos obligacionales. Seguidamente se formularán las viii) conclusiones ${ }^{23}$.

\subsection{La problemática del desplazamiento forzado de personas en Colombia}

Los estudios sobre desplazamiento forzado en Colombia han sido cuantiosos y en ellos se ha abordado el problema desde toda perspectiva, entre otras, a partir de la condición de los sujetos que ostentan una especial protección constitucional como sucede con los campesinos, indígenas, madres cabeza de familia, personas de la tercera edad, comunidad afrocolombiana ${ }^{24}$, etc.; sin embargo, sin importar el enfoque sobre el derecho vulnerado o la condición de la persona en particular o el lugar donde ocurra la tragedia ${ }^{25}$, esta es una realidad que puede condensarse en el siguiente iter fáctico:

- Existe una persona o grupo familiar que vive en un determinado lugar del territorio en Colombia, propiedad en la que se ha desarrollado toda una vida -ámbito religioso, educación, laboral, económico, productivo, recreativo, amoroso-;

- Se presenta una coacción consistente en la amenaza o la lesión a la persona o grupo de personas en un contexto geográfico, lo cual impulsa el abandono o genera la expulsión de la propiedad o lugar que se habita;

- Se recorre un camino hacia cualquier parte de la geografía colombiana, no elegido por voluntad propia, quizás al encuentro de algún familiar o simplemente a la capital o municipio del departamento;

- Se arriba a un lugar donde las condiciones de vida oscilan entre las acrobacias de la indigencia y los malabarismos de la mendicidad, evidente principalmente en los semáforos de nuestras ciudades, sin la posibilidad de una satisfacción efectiva e inmediata de un mínimo vital.

\footnotetext{
${ }^{23}$ La presente investigación se tipifica dentro de un enfoque de investigación cualitativo, con un tipo de investigación descriptivo, correlacional y explicativo, en el cual se emplean como instrumentos de investigación la ficha de análisis normativo, jurisprudencial y documental, utilizando como técnica de investigación el análisis de contenidos. Consúltese al respecto: CLAVIJO et al. (2014), pp. 1-105.

${ }^{24}$ Consúltese al respecto: Rodríguez et al. (2009), pp. 1-271.

${ }_{25}$ Consúltese al respecto: MuÑoz et al. (2009), pp. 1-475.
} 


\subsection{El juicio de responsabilidad del Estado por desplazamiento forzado en la jurisprudencia del Consejo de Estado colombiano ${ }^{26}$}

Las subreglas ${ }^{27}$ definidas por el Consejo de Estado para definir la responsabilidad o irresponsabilidad del Estado colombiano, en la línea jurisprudencial existente por desplazamiento forzado como problema propio al sistema subjetivo de responsabilidad del Estado dentro del régimen de la falla en la prestación del servicio de seguridad y protección ${ }^{28}$, se identifican al siguiente tenor:

i. Existencia de un daño antijurídico; conforme al objeto de investigación se encuentra en el desplazamiento forzado.

ii. Imputación del daño; quien resulta eventualmente responsable es La nación-Ministerio de Defensa-Ejército Nacional-Policía Nacional.

iii. Atribución de contenidos obligacionales incumplidos -absoluta, parcial o tardíamente- por el sujeto imputado, establecidos en la Constitución y su sistema normativo.

iv. Relevancia jurídica dentro del proceso causal de producción del daño, acción u omisión y el daño en sí mismo.

v. En esta etapa debe referirse que el estudio del nexo se altera -atenúa- en seguimiento de la teoría de la posición de garante.

vi. Existencia y prueba de los perjuicios causados.

Conforme a lo anterior, si el juez contencioso administrativo encuentra que cada uno de estos elementos axiológicos resultan probados en el proceso, declara la responsabilidad o irresponsabilidad patrimonial y administrativa del Estado por desplazamiento forzado, con la consecuente referencia a las medidas de reparación integral en las distintas tipologías de perjuicios que reconoce la Ley y la jurisprudencia de resultar condenado.

Una de las particularidades diferenciadoras de este juicio de responsabilidad en la falla del servicio se presenta en el necesario conocimiento previo que debe tener la administración pública sobre los hechos de coacción que pueden impulsar el traslado, noticia y prueba que de faltar en el proceso podrían definir la inexistencia de la falla y, consecuentemente, de

${ }^{26}$ Consúltese al respecto: YáñEZ (2013 b), pp. 13-46. El presente capítulo encuentra desarrollo completo y detallado en la cita de la referencia.

27 LóPEZ (2006), pp. 1-366.

${ }^{28}$ ambitojuridico.com (2014). En reciente publicación de ámbito jurídico en junio 24 del año 2014 se destacó la noticia en torno a las demandas que se presentan contra el Estado, esta se tituló: Más de 30.000 demandas contra el Estado se presentaron en los cinco primeros meses del año. Dentro de las causas más costosas para el Estado al mes de mayo se encuentra en tercer lugar el incumplimiento del deber de seguridad y protección por parte del Estado, cuyo monto asciende a los 28.553.317.302 pesos. La principal causa es la privación injusta de la libertad, la cual asciende a 88.015.556.235 pesos, seguida por la ilegalidad del acto administrativo que impone una sanción fiscal que asciende a 42.478 .347 .288 . 
la responsabilidad. Aunque bajo la teoría de la posición de garante la prueba del nexo disminuye junto a la exigencia de una teoría de la relación de causalidad, con lo cual puede afirmarse podría tenderse a la futura y paulatina eliminación de la exigencia, aún se requiere de la noticia previa para configurar la responsabilidad. La posición de garante permite descubrir la falla en el contraste existente entre los contenidos obligacionales de carácter constitucional, legal o reglamentario que se incumplieron en forma absoluta, parcial o tardía y el daño que se alega como antijurídico, sin desaparecer la causalidad, pero atenuándola significativamente a partir de la competencia del órgano a quien se le encomienda la protección en el monopolio de la fuerza dentro de la estructura del Estado.

En punto de reparación integral, salvo declaratoria de la existencia, condena y cuantificación del daño moral y por alteración de las condiciones de existencia, las restantes tipologías del daño -daño emergente, lucro cesante, etc.- no encuentran reconocimiento en las sentencias, aunque se decida su condena en abstracto. El aspecto diferenciable en este juicio se identifica en que producto de la evolución del juicio de responsabilidad del Estado por desplazamiento forzado en la jurisprudencia del Consejo de Estado, en el reconocimiento de una de las consecuencias más graves del conflicto armado interno colombiano, sus efectos son tan graves que sobre el acontecimiento de su suceso constituyen hechos notorios ${ }^{29}$ la ocurrencia de dos tipologías del perjuicio: el moral y por alteración de las condiciones de existencia.

En el aspecto temporal, la línea jurisprudencial existente en la resolución del problema jurídico revela que las víctimas esperan entre 4,7 años, cuando se formula una pretensión de grupo, y 11,10 años cuando se formula una pretensión de reparación directa para que no se reconozca la existencia del daño y sus perjuicios, o solo le sea concedida la reparación del perjuicio moral y por alteración de las condiciones de existencia, y para que, en ocasiones, se condene en abstracto respecto a las restantes tipologías del perjuicio -emergente, lucro cesante, etc.-, lo cual puede ampliar ese instante del proceso a 6 o 7 años o 13 o 14 años respectivamente.

En cuanto a la cuantificación del perjuicio, la línea jurisprudencial descubre diferencias sustanciales entre la reparación del perjuicio a través de la acción de reparación directa y la acción de grupo. En esta última, en ocasiones, se condena por el perjuicio moral al pago de 50 salarios mínimos legales mensuales vigentes -en adelante smlmv- por persona, en otras, en rubor conjunto

${ }^{29}$ Corte Constitucional. Sentencia de Constitucionalidad 145. Marzo 12 del 2009. La Corte Constitucional ha definido el hecho notorio en multiplicidad de decisiones como "...aquél cuya existencia puede invocarse sin necesidad de prueba alguna, por ser conocido directamente por cualquiera que se halle en capacidad de observarlo. Según el artículo 177 del C.P.C., los hechos notorios no requieren prueba". 
al lado del perjuicio por alteración a las condiciones de existencia, también se condena por $50 \mathrm{smlmv}$; asimismo, cuando se ha compensado independientemente el perjuicio por alteración a las condiciones de existencia se condenó por $25 \mathrm{smlmv}$. Cuando se utiliza la acción de reparación directa el perjuicio por alteración a las condiciones de existencia se condena por $50 \mathrm{smlmv}$ y por el perjuicio moral a $100 \mathrm{smlmv} v^{30}$.

\subsection{Las medidas cautelares en el juicio de responsabilidad del Estado por desplazamiento forzado en Colombia}

Un examen de la totalidad de providencias emitidas por el Consejo de Estado frente a la resolución del problema jurídico planteado refleja la inexistencia absoluta de petición o decreto alguno por el juez en la lógica del poder cautelar. En vigencia del CCA -1981- la medida cautelar única y exclusiva del proceso administrativo -suspensión provisional del acto administrativo- impedía que el juez en los procesos de responsabilidad extracontractual del Estado emitiera medidas cautelares frente a la pretensión pecuniaria o de cualquiera otra naturaleza. Por lo anterior, no existe antecedente alguno sobre el papel de las medidas cautelares en los procesos de responsabilidad del Estado en general $y$, en particular, por desplazamiento forzado.

Con la expedición del CPACA -2011-, de una parte, la realidad normativa del derecho del proceso administrativo evoluciona. Con la consagración de un conjunto de nuevas formas de actuación del juez para la protección de la pretensión en la eventual sentencia, el operador jurídico puede decretar medidas cautelares de contenido y alcance preventivo, conservativo, anticipativo, de suspensión yde urgencia; de otra, en virtud del CGP -2012- la solicitud, decreto, práctica, modificación, sustitución y revocatoria de las medidas cautelares se posibilita en "Cualquiera otra medida que el juez encuentre razonable para la protección del derecho objeto del litigio, impedir su infracción o evitar las consecuencias derivadas de la misma, prevenir daños, hacer cesar los que se hubieren causado o asegurar la efectividad de la pretensión" ${ }^{\prime 31}$, con lo cual se crea, para algunos ${ }^{32}$, la medida cautelar innominada conforme a lo establecido en el artículo 590 literal c) ${ }^{33}$.

30 Consúltese al respecto: YÁÑEZ (2013 b), pp. 13-46.

31 Consúltese al respecto: Forero (2013), pp. 25-28.

32 Si bien la Doctrina predica en Colombia que fue el Código General del Proceso la disposición que crea las medidas cautelares innominadas, Ley N 1564, de 2012, es discutible esta posición en razón a que desde el Código de Procedimiento Administrativo y de lo Contencioso Administrativo, Ley № 1437, de 2011, se consagraron las diferentes formas de intervención cautelar -preventiva, anticipatoria, de urgencia, suspensión, conservatorias- en las que finalmente se materializa la cautela innominada.

33 Ley $N^{0} 1564$, de 2012. 
De esta forma, puede afirmarse que la imaginación, la apariencia de buen derecho, el peligro en la demora y la proporcionalidad de la medida, se presentan como los límites que enfrenta el juez en el momento en que se le solicita una medida cautelar, sin importar la naturaleza de la pretensión o medio de control del caso. Dada la reciente vigencia de estas instituciones el ejercicio del derecho en el litigio y la decisión judicial, no es posible determinar qué nuevas pretensiones cautelares se han solicitado y un estudio selectivo en las decisiones del Consejo de Estado colombiano, a partir de la entrada en vigencia del CPACA y el CGP, demuestra que la suspensión provisional sigue siendo la única medida cautelar que se emplea en los procesos que se ventilan ante el juez administrativo ${ }^{34}$.

La desprotección de la condición de la persona víctima de desplazamiento forzado en el poder cautelar es manifiesta y el derecho procesal en este punto debe responderle a la víctima, quien ante la tragedia prolongada de vida que enfrenta podría encontrar en la cautela un medio eficaz para la protección de sus derechos. La calidad de sujetos de especial protección constitucional y el principio de discriminación positiva que la jurisprudencia constitucional en Colombia emplea le permiten al juez respaldar su decisión cautelar.

\subsection{Las medidas cautelares y provisionales en el juicio de responsabilidad internacional de los Estados por desplazamiento forzado}

En el ámbito de protección internacional de los derechos humanos del Sistema Interamericano de Derechos Humanos, la Corte Interamericana de Derechos Humanos y la Comisión Interamericana de Derechos Humanos han emitido medidas cautelares y provisionales frente a la situación de las personas víctimas de desplazamiento forzado. En numerosas ocasiones el juez y órgano cuasi-jurisdiccional ${ }^{35}$ han ordenado a los Estados i) la protección eficaz e inmediata de la vida e integridad personal de los desplazados y ii) frente a la garantía de las condiciones de seguridad necesarias para que se respete el derecho a la libre circulación de las personas y de aquellos que se vieron forzados a desplazarse a otro lugar para que puedan regresar a sus hogares si lo desean ${ }^{36}$.

\footnotetext{
${ }^{34}$ Consejo de Estado. Auto 1973-12. Agosto 29 del 2013.

35 Corte Constitucional. Sentencia de Tutela 524. Mayo 20 de 2005.

36 Comisión Interamericana de Derechos Humanos. Resolución Caso Comunidad Noman del Pueblo Indígena Wounaan. Junio 3 del 2011.

Comisión Interamericana de Derechos Humanos. Resolución Caso Comunidad de Paz de San José de Apartadó. Noviembre 24 del 2000.

Corte Interamericana de Derechos Humanos. Resolución Caso Masacre La Rochela. Noviembre 19 del 2009.
} 
El juez contencioso administrativo en Colombia en los procesos de responsabilidad extracontractual, se reitera, no ha adoptado ninguna decisión en la lógica del poder cautelar. Se considera que en razón al carácter vinculante de estas decisiones ${ }^{37}$ y su virtualidad en la protección inmediata y efectiva de los derechos y el amplio poder cautelar que posee desde el CPACA, el juez colombiano debe asimilar las estrategias que desde la jurisprudencia internacional se desarrollan al ser una interpretación autorizada de los derechos humanos.

En virtud del bloque de constitucionalidad y su evolución en los estándares internacionales en materia de derechos humanos conforme al sistema de fuentes del derecho en Colombia ${ }^{38}$, el juez puede emitir una decisión cautelar de iguales proporciones a las proferidas en el Sistema Interamericano. Sin embargo, a pesar de que desde el año 2000 el Estado ha recibido este tipo de órdenes cautelares y provisionales, el juez contencioso en Colombia no ha advertido o teme dar aplicación a la particularidad vigente en estos casos.

Esta dualidad en la forma de protección crea un derecho distinto frente a los mismos hechos dependiendo si se está en sede de responsabilidad internacional o de responsabilidad interna -en Colombia-; esta diferenciación crea indiscutiblemente una ventaja en el derecho del juez internacional. Si bien se considera que aún sin los cambios que introdujo el CPACA, el juez en Colombia en virtud del bloque podía adoptar este tipo de medidas, entendiendo el temor y la inexistencia en la aplicación de estas en virtud del principio de legalidad, con la adopción de este nuevo Código es incuestionable que los dos sistemas deben empezar a ser consonantes, entre otras materias, en punto de medidas cautelares y provisionales.

De tal forma que el derecho de las víctimas en la garantía cautelar no tiene que verse diferido en el tiempo hasta la instancia internacional, la decisión cautelar en el proceso de responsabilidad nacional permitiría eventualmente que la continuidad de la condición de desplazado cesará con mayor prontitud, lo cual traería consigo la disminución, por ejemplo, de las cuantías que por lucro cesante y daño emergente pueden pretenderse en el eventual proceso de responsabilidad, lo cual desde una perspectiva de prevención de las consecuencias del daño, indudablemente, disminuiría los posibles montos a cargo del Estado en una posterior condena de perjuicios en la sentencia.

37 Corte Constitucional. Sentencia de Tutela 786. Septiembre 11 de 2003.

38 Consúltese al respecto: YáÑEz (2012), pp. 7-34. 


\subsection{La necesidad y suficiencia de la medida cautelar innominada-conservativa en la protección del derecho fundamental a la propiedad}

En la protección efectiva de los derechos fundamentales, el tiempo que pasa es la verdad que huye junto a la justicia,

la legitimidad del Estado y el derecho sustancial

El Autor

El derecho a la propiedad para las personas víctimas del desplazamiento forzado, al tratarse de sujetos que ostentan una especial protección constitucional, adquiere la calidad de derecho fundamental en términos de reiterada jurisprudencia de la Corte Constitucional ${ }^{39}$. La propiedad y su aseguramiento en punto de medidas de protección y seguridad tiene la potencialidad de atenuar, adicionalmente, la causación prolongada de ciertas tipologías del perjuicio, particularmente frente a sus contenidos indemnizatorios en el daño emergente y el lucro cesante; al garantizárseles a las víctimas un retorno con inmediatez al éxodo con garantías de no repetición, el Estado mitigaría la posterior condena frente al pago de sumas más elevadas por el natural transcurso del tiempo.

Al emitir una medida cautelar en orden que garantice el retorno con garantías de seguridad y protección, el Estado asegura eficazmente los derechos comprometidos como exigencia propia a la posición de garante que posee frente a los derechos de las víctimas de conformidad a los tratados internacionales que le asignan esa función. En este contexto, la Corte Interamericana de Derechos Humanos, en resolución sobre medida provisional ha sostenido:

Que...la protección de una pluralidad de personas que han sido previamente nominadas, pero que son identificables y determinables y que se encuentran en una situación de grave peligro en razón de pertenencia de un grupo o comunidad. Las comunidades constituidas por el consejo comunitario del Jiguamiandó y las familias que conformaban 515 familias, constituye una comunidad organizada ubicada en un lugar geográfico determinado en el municipio de Carme de Darién, departamento del Chocó, cuyos miembros pueden ser individualizados e identificados y por el hecho de formar parte de dicha comunidad, todo se encuentra en una situación de igual riesgo de sufrir actos de agresión, contra su actividad personal y su vida, así como verse desplazados forzadamente de su territorio, situación que les impide explotar sus recursos necesarios para su subsistencia.

${ }^{39}$ Corte Constitucional. Sentencia de Tutela 159. Marzo 10 de 2011. 
Que dada la situación que se vive en las comunidades de Jiguamiandó y el Curvaradó ha obligado a sus pobladores a desplazarse a otras regiones del país, es necesario que el Estado asegure que las personas beneficiadas con las presentes medidas puedan seguir viviendo en su residencia habitual y brinde las condiciones necesarias para que las personas de dicha comunidad que se hayan visto forzadas a desplazarse regresen a sus hogares ${ }^{40}$.

Para esta clase de medida la apariencia de buen derecho se prueba con i) el acto administrativo emitido por el Departamento Administrativo de la Prosperidad Social (o quien fuera competente) a través del cual se le reconoce la condición de desplazado a la persona y a su núcleo familiar ${ }^{41}$, ii) la calidad de sujeto que ostenta una especial protección constitucional, iii) la existencia de declaración formal de un Estado de Cosas Inconstitucional frente a su condición, iv) la efectiva posibilidad de aplicar un enfoque de discriminación positiva que genere la acción del Estado a fin de garantizar la igualdad material frente al derecho a la reparación.

El peligro en la demora se prueba con i) la verificación sobre la inexistencia de condiciones mínimas para asegurar un mínimo vital, ii) la amenaza de que las tierras abandonadas sean invadidas por terceros, razón que se evidencia en la política pública de restitución de tierras ${ }^{42}$ y iii) la efectiva amenaza sobre el derecho a que no le sean atacados, destruidos, sustraídos o inutilizados artículos alimenticios, derecho a que no le sea atacada, destruida, sustraída o inutilizada la zona que produce el alimento, derecho a que no le sea atacada, destruida, sustraída o inutilizada la cosecha, derecho a que no le sea atacado, destruido, sustraído o inutilizado el ganado, derecho a que no le sea atacada, destruida, sustraída o inutilizada las instalaciones y reservas de agua potable, derecho a que no le sean atacadas, destruidas, sustraídas o inutilizadas las obras de riego, derecho a que no le sean atacados, destruidos, sustraídos o inutilizados los bienes indispensables para la supervivencia, todos ellos derivados de los Principios Rectores de los Desplazamientos Internos creados por la $\mathrm{ONU}^{43}$.

\footnotetext{
40 Corte Interamericana de Derechos Humanos. Resolución Caso Comunidades del Jiguamiandó y del Curvaradó. Febrero 7 de 2006.

Corte Interamericana de Derechos Humanos. Resolución Caso Comunidades del Jiguamiandó y del Curvaradó. Mayo 22 del 2013.

${ }^{41}$ Debe señalarse que el acto administrativo no otorga la condición de desplazado, esto en razón a que esta condición se deriva de una situación de hecho y no en virtud de una declaración de una autoridad administrativa. Sin embargo, es claro que la existencia del acto administrativo facilita la prueba del elemento daño dentro del juicio de responsabilidad.

42 Para un examen adecuado de las decisiones proferidas por la Corte Constitucional frente a la política estatal de restitución de tierras pueden analizarse las siguientes decisiones: A-087-13, A-101-13, T-821-07, T-159-11, C-715-12, C-438-13, T-699A-11.

${ }_{43}$ Resolución E/CN.4/1998/53/Add.2, de 1998.
} 
La proporcionalidad de la medida se justifica por cuanto la tragedia de las víctimas es incontrovertible frente al derecho, al no existir otro medio que permita garantizar el derecho en igualdad de condiciones como se asegura a través de la medida cautelar.

\subsection{La necesidad y suficiencia de la medida cautelar innominada-anticipativa frente a la pretensión económica en la reparación del perjuicio moral y por alteración de las condiciones de existencia}

La función de las medidas cautelares nace de la relación que se establece entre dos términos: La necesidad de que la providencia, para ser prácticamente eficaz, se dicte sin retardo, y la falta de aptitud del proceso ordinario para crear sin retardo una providencia definitiva ${ }^{44}$

En el juicio de responsabilidad del Estado por desplazamiento forzado a través del medio de control de reparación directa y de grupo, se construye la responsabilidad del Estado a partir de un juicio subjetivo de responsabilidad en la falla de la prestación del servicio de seguridad y protección. Un estudio detallado de la línea jurisprudencial en las decisiones del Consejo de Estado colombiano permite aseverar que bajo la ocurrencia de estos sucesos quien resulta imputado y posteriormente responsable es el Ejército y la Policía Nacional.

La apariencia de buen derecho frente a la pretensión cautelar que asegure la orden de pago en la compensación de este daño a la víctima sobre el perjuicio moral y por alteración de las condiciones de existencia se identifica en i) la tesis jurisprudencial en virtud de la cual el perjuicio moral en el juicio de responsabilidad es un hecho notorio ii) la tesis jurisprudencial en virtud de la cual el perjuicio por alteración de las condiciones de existencia es un hecho notorio, iii) la construcción del precedente jurisprudencial, desde la línea jurisprudencial, a partir del examen de la totalidad de decisiones que ha emitido el Consejo de Estado frente al problema jurídico de responsabilidad patrimonial y administrativa del Estado, y sobre los cuales es posible identificar las subreglas o elementos axiológicos que permiten al juez establecer la responsabilidad o la irresponsabilidad del Estado y que, en el caso concreto, puede llevarse al conocimiento del juez en su adecuación particular en la petición cautelar, iv) la aplicación de la teoría de la posición de garante para la construcción de la falla en la prestación del servicio; teoría que atenúa el examen del nexo de causalidad en la concepción de una falla que se determina en una teoría normativa, v) la violación sistemática, continua, manifiesta y grave a los derechos fundamentales.

${ }^{44}$ Calamandrei (1962). 
El peligro en la demora en la pretensión cautelar en la reparación en su modalidad de compensación se verifica en i) el término irrazonable del proceso ordinario en sede administrativa para declarar la responsabilidad del Estado, el cual puede prolongarse hasta 4,7 años cuando se presenta la pretensión de grupo y 11,10 años cuando se formula la acción de reparación directa, ii) la condena que se impone transcurrido este tiempo, en exclusiva, sobre el perjuicio moral y por alteración de las condiciones de existencia, es decir, la víctima aguarda este tiempo para que al final se le reconozcan tipologías del perjuicio que son hechos notorios y iii) la necesidad de los dineros para alcanzar estándares mínimos de satisfacción en el goce efectivo de los derechos fundamentales de la víctima y el núcleo familiar desplazado.

La pretensión de medida cautelar innominada, conforme a las cuantías de las condenas que ha proferido el Consejo de Estado en su línea jurisprudencial permiten asignar una estimación razonada de la cuantía en el valor de 100 smlmv por el perjuicio moral y de $50 \mathrm{smlmv}$ por el perjuicio por alteración de las condiciones de existencia. Sin duda alguna, frente al incontrovertible incumplimiento de contenidos obligacionales constitucionales, legales, reglamentario, entre otros, en cuanto a la inexistencia en el monopolio de la fuerza por parte del Estado y la tragedia desproporcionada en el modo de vida, la medida cautelar que asegure el pago anticipado de estos perjuicios le permitiría a la víctima poseer una mejor expectativa frente a la tragedia que enfrenta.

\subsection{La orden cautelar en el pago de sumas de dinero derivadas del incumplimiento total, parcial o tardío de contenidos obligacionales}

En el ámbito internacional, frente a la garantía de pretensiones pecuniarias y la concesión de pagos de sumas de dinero en virtud de una orden cautelar existe un referente importante en el derecho español. Es claro que la idea que persigue alcanzar, que cautelarmente se reconozca el pago de eventuales perjuicios causados, es discutible por cuanto la lógica tradicional enseña que, por ejemplo, si se quiere asegurar una deuda la decisión cautelar que asegura la pretensión es, por ejemplo, el embargo, jamás el pago, además porque se resolvería sobre el fondo de la causa. Frente a ello, debe aclararse que la tesis que en este artículo se expone se circunscribe al daño causado a las víctimas de desplazamiento forzado, no un Ilamado generalizado a todos los procesos de responsabilidad del Estado, aunque el caso español al que se hizo referencia no es en esta materia el debate se pone de presente.

En la providencia en comento, del año 2013, se adoptó una medida cautelar dentro de un proceso contencioso administrativo, a solicitud de la Universidad del País Vasco, frente a la inactividad de la Administración General del Estado (Ministerio de Ciencia e Innovación), en relación a un Convenio suscrito, en el año 2010, en el que se concede una subvención nominativa dispuesta en 
los presupuestos generales del Estado para el año 2010. La medida acordada consistió en la transferencia de tres millones de euros a la Universidad, importe de la subvención nominativa otorgada por el Convenio correspondiente al ejercicio para el año $2011^{45}$.

En el caso la Sala de lo Contencioso Administrativo, Sección Tercera, de la Audiencia Nacional adoptó la medida cautelar de "requerir a la Administración demandada para que procediese a transferir a la Universidad demandante la cantidad de 3.000.000 en concepto de subvención nominativa no abonada".

En concreto se verificó el incumplimiento de contenidos obligacionales adquiridos en virtud del Convenio y el vencimiento de los plazos allí establecidos frente a la subvención a causa de la inactividad administrativa, lo cual tornó adecuada la orden. Frente a la ponderación circunstanciada de los intereses en conflicto para adoptar la medida cautelar, al no haberse tenido en cuenta el contexto de crisis económica y las dificultades presupuestarias alegadas por el Estado, el Tribunal consideró:

"...Si bien tales medidas suelen requerir la presencia de un fumus boni iuris fundado, ello no implica pronunciarse sobre el fondo, puesto que la decisión final no está en modo alguno predeterminada por la medida cautelar que, como toda la justicia cautelar, trata tan solo de preservar que el recurso no pierda su finalidad como consecuencia de la dilación en resolver. En consecuencia, ningún obstáculo existe para que en determinados supuestos concretos y sin que puedan hacer afirmaciones genéricas, pueda adoptarse una medida positiva en supuestos de inactividad administrativa contemplados en el artículo 29.1 y al sólo objeto de evitar la posible pérdida de finalidad del recurso, tal como se prevé expresamente en el artículo 136 de la propia Ley jurisdiccional. En puridad, una interpretación como la propuesta por el Abogado del Estado resulta contradictoria con lo previsto en el citado artículo 136, referido a la posibilidad de adoptar medidas cautelares en los supuestos de inactividad administrativa o vías de hecho, lo que resultaría imposible de entender que en tales casos la medida cautelar - presumiblemente de carácter positivo en los supuestos de inactividad administrativa- prejuzga inevitablemente el fondo del asunto.

No tiene razón la Administración, puesto que la Sala de instancia ha ofrecido una valoración razonable de los intereses en conflicto en las resoluciones impugnadas, especialmente en el fundamento jurídico cuarto del segundo Auto, en el que se rechaza de forma expresa la apelación al interés general relativo a

45 Tribunal Supremo. Sala de lo Contencioso Administrativo Sección Tercera. Recurso Casación 4586. Noviembre 19 de 2013. 
los objetivos de I+D+I aducido por la Administración, entendiendo que dicho interés está también presente en la posición defendida por la Universidad. Y la argumentación que la Sala de instancia ofrece a continuación no es sino una crítica a la generalidad con que la Administración ha apelado al interés público, impidiendo con ello que la Sala pudiera apreciar debidamente la afectación de los mismos alegada por la propia Administración. No existe, por tanto, la infracción que se denuncia, sino que la Sala ha motivado de forma razonable la ponderación de intereses en función de los datos y argumentos que se le han presentado..." 46

Frente al problema jurídico planteado en esta investigación, el desconocimiento de contenidos obligacionales en el acontecimiento del desplazamiento forzado goza de una entidad superior a la del ejemplo expuesto, contenidos obligacionales de carácter constitucional, legal, reglamentario, internacionales en instrumentos de hard law y soft law y los construidos desde la jurisprudencia constitucional se incumplen, de esta manera se construye a plenitud el fumus boni iuris. De otra parte, el argumento presupuestal no puede constituirse en una causa suficiente para el desconocimiento justificado de la irresponsabilidad o la reparación en la orden de pago cautelar; no puede aceptarse que la razón de tiempo atrás siga siendo la misma. Un ejercicio práctico clarifica en forma adecuada nuestra posición en la procedencia de las órdenes que se han analizado:

Imaginemos que por alguna circunstancia se es víctima de un desplazamiento forzado o alguno de nuestros familiares. ¿Qué ofrece el ordenamiento jurídico

${ }^{46}$ La Sala de instancia motivó al respecto: "Cuarto. Se arguye también en reposición que la medida ocasionaría una perturbación grave de los intereses generales al poner en riesgo el cumplimiento de los objetivos de la política de I+D+l, alegándose también que la no autorización por el Ministerio de Economía y Hacienda se justificó en la falta de ritmo de ejecución y necesidad de financiación de la actuación financiada que se había visto retrasada en más de un año por causas ajenas a la propia Administración". "Tampoco este motivo recursivo puede prosperar". "Se aduce por el Abogado del Estado el retraso padecido en la actividad financiada, pero no puede desconocerse que se trataba de una subvención nominativa con pago anticipado y que el propio Ministerio de Ciencia e Innovación por resolución 15-11-2011 autorizó la prórroga hasta el 31-12-2012 para la ejecución de las actividades subvencionadas. Este Tribunal no pone en duda el interés general de os objetivos de I+D+I a que de forma genérica se alude en el recurso de reposición, pero es de entender que dicho interés general está también ínsito en el objeto subvencionado de autos, dotado además en los presupuestos generales del Estado. por otra parte, el artículo 136.1 de la LJ exige que el órgano judicial pondere la perturbación grave de los intereses generales "en forma circunstanciada", cuya ponderación "en forma circunstanciada" no resulta hacedera en las actuales condiciones, en las que la no autorización por el Ministerio de Economía y Hacienda se hizo con una motivación en cierta forma genérica y siguiendo las pautas marcadas por el acuerdo del Consejo de Ministros de 22-7-2011, cuyo carácter genérico también es predicable de la invocación que se hace en el recurso de reposición de la afectación de los intereses generales en relación con los objetivos de I+D+I. En tales condiciones que resultan en función de lo actuado malamente puede la Sala hacer una ponderación "en forma circunstanciada", sin que por mor de lo dicho dispongamos de suficientes elementos de juicio para afirmar que la medida cautelar causa "una perturbación grave de los intereses generales". 
colombiano, desde una perspectiva judicial de la reparación, frente a los perjuicios causados?, el proceso judicial en la reparación directa y la acción de grupo con todas las etapas tradicionales de estos procesos; primer problema: el régimen de responsabilidad en la falla del servicio de seguridad y protección, el cual exige para la declaratoria de responsabilidad o irresponsabilidad del Estado el conocimiento previo de la autoridad, en otros términos, bajo este sistema a pesar de la amenaza y vulneración grosera a los derechos, intereses y bienes de las personas, el Estado es irresponsable por su incapacidad manifiesta; segundo problema: la duración irrazonable del proceso tradicional, el cual le ofrece a la víctima entre 4,7 y 11,10 años de espera para que se repare el perjuicio moral y por alteración de las condiciones de existencia y una condena en abstracto respecto del reconocimiento de los perjuicios pecuniarios. En otros términos, no existe una tutela jurisdiccional efectiva. Las medidas cautelares que se proponen son un instrumento adecuado para la protección de los derechos; sin duda, el poder cautelar está Ilamado a remediar los problemas derivados de la congestión judicial, el retardo justificado o injustificado, y a colmar los gritos desesperados de la justicia que huye con el transcurso del tiempo.

\section{Conclusiones}

La medida cautelar innominada sobre la pretensión pecuniaria en la reparación del perjuicio moral y por alteración de las condiciones de existencia es de naturaleza anticipativa; la medida cautelar innominada sobre la pretensión de garantías de seguridad y protección en el lugar de expulsión para la garantía del derecho de propiedad es de naturaleza conservativa.

Las consecuencia del daño causado y su reparación integral no puede depender del discurso en torno a la existencia o inexistencia de recursos para cubrir la condena; por el contrario, debe concebirse como un elemento consustancial al Estado Constitucional, Social y Democrático de Derecho, en un esfuerzo por afianzarse y legitimarse ante una realidad concreta de prestación inadecuada de un servicio que causa un daño a los derechos fundamentales.

La medida cautelar innominada-anticipatoria frente a la pretensión del reconocimiento en el pago del perjuicio moral y por alteración de las condiciones de existencia, es posible en el contexto del proceso de responsabilidad del Estado por desplazamiento forzado en la acción de reparación directa y la acción de grupo, estos conforme a la línea jurisprudencial existente deben reconocerse en la orden de pago cautelar en cien -100- y cincuenta -50- salarios mínimos legales mensuales vigentes $-S M L M V$ - respectivamente.

La medida cautelar innominada-conservatoria frente a la protección del derecho de propiedad permite que el Estado, en la lógica del carácter preventivo de la responsabilidad, garantice en forma efectiva los derechos comprometidos 
con el desplazamiento forzado y disminuya las pretensiones económicas que, en lo sucesivo, puedan presentarse en los procesos que persigan la responsabilidad del Estado, particularmente frente a las tipologías del perjuicio pecuniario -perjuicio emergente y lucro cesante-. Este tipo de medida es un reflejo de la lógica propia a las decisiones proferidas en el Sistema Interamericano de Derechos Humanos, que el juez contencioso en Colombia debe empezar a adoptar, el nuevo contexto normativo favorece el sustento de legalidad que antes no poseía.

\section{Bibliografía CitADA}

Alpargatero Ulloa, Leidy Liliana (2011): La política pública de desplazamiento forzado en Colombia: una visión desde el pensamiento complejo (Bogotá, Editorial Universidad del Rosario).

Álvarez Díaz, Oscar Luis (2008): Estado social de derecho, Corte Constitucional y desplazamiento forzado en Colombia (Bogotá, Siglo del Hombre Editores, Universidad Nacional de Colombia, Pontificia Universidad Javeriana).

BAlCÁZAR Quiroz, José (2010): Teoría de las medidas autosatisfactivas. Una aproximación desde la teoría general del proceso (Lima, ARA Editores E.I.R.L.).

Calamandrel, Piero (1962): Instituciones de derecho procesal civil. Según el nuevo código, segunda edición (Traducc. Santiago Sentís Melendo, Buenos Aires, Ediciones Jurídicas Europa-América), volumen I.

CalAmandReI, Piero (2005): Introducción al estudio sistemático de las providencias cautelares (Lima, ARA Editores E.I.R.L.).

Clavijo Cáceres, Darwin; Guerra Moreno, Débora y Yáñez Meza, Diego Armando (2014): Método, metodología y técnicas de investigación aplicada al derecho (Bogotá, Grupo Editorial Ibáñez y Universidad de Pamplona).

FÁBreGA, Jorge (1998): Medidas cautelares (Bogotá, Ediciones Jurídicas Gustavo Ibáñez Ltda.)

Forero Silva, Jorge (2013): Medidas cautelares en el Código General del Proceso (Bogotá, Editorial Temis S.A.).

Gozaínı, Osvaldo Alfredo (2013): “¿Tutela diferente o privilegiada?", en: Congreso Internacional de Derecho Procesal (Vol. 2, № 2), pp. 41-57.

LóPEZ MeDina, Diego Eduardo (2006): El derecho de los jueces. Obligatoriedad del precedente constitucional, análisis de sentencias y líneas jurisprudenciales y teoría del derecho judicial, segunda edición (Bogotá, Legis Editores S.A.).

MARINONI, Luiz Guilherme (2010): Tutelas urgentes y tutelas preventivas (Lima, Librería Communitas).

Muñoz Restrepo, Alba Luz, et al. (2009): Derechos de la población desplazada (Estudio de caso en la ciudad de Medellín). Un análisis teórico, legal y jurisprudencial de los derechos a la salud, la educación, la vivienda y el 
empleo -proyectos productivos- de la población en situación de desplazamiento. Análisis de la ruta de atención a la población desplazada en la ciudad de Medellín (Medellín, Sello Editorial Universidad de Medellín y Personería de Medellín).

Peña Díaz, Carlos Mario (2011): Reparación integral. Consideraciones críticas. Una aproximación a la jurisprudencia del Consejo de Estado y de la Corte Interamericana de Derechos Humanos (Bogotá, Ediciones Veramar).

Rodríguez Garavito, César; Alfonso Sierra, Tatiana y Cavelier Adarve, Isabel (2009): El desplazamiento afro. Tierra, violencia y derechos de las comunidades negras en Colombia (Bogotá, Universidad de los Andes).

Sarmiento Erazo, Juan Pablo (2013): "La transformación de la responsabilidad administrativa a la luz de la Constitución de 1991. El caso de la responsabilidad del Estado por desplazamiento forzado", en: El derecho público y los veinte años de la Constitución de 1991 (Bogotá, Universidad de los Andes), pp. 217-147.

Yáñez MeZA, Diego Armando (2012): "Las fuentes del derecho en la Constitución Política de 1991: una teoría que plantea la existencia de dos jueces distintos", en: Revista Academia \& Derecho (Vol. 5, № 5), pp. 7-34.

Yáñez MeZA, Diego Armando (2013 a): "El desplazamiento forzado en la jurisprudencia de la Corte Constitucional colombiana (1991-2003): momento previo a la declaratoria formal del Estado de Cosas inconstitucional", en: Revista Justicia (№ 23), pp. 191-218.

Yáñez MeZA, Diego Armando (2013 b): "Responsabilidad extracontractual del Estado por desplazamiento forzado de personas. Construcción de la línea jurisprudencial en las decisiones del Consejo de Estado", en: Revista Civilizar. Ciencias Sociales y Humanas (Vol. 13, No 24), pp. 13-46.

Unidad para la atención y reparación integral a las víctimas (2014): "Reporte general, desagregado por hecho, desplazamiento". Disponible en: http://rni. unidadvictimas.gov.co/?q=v-reportes [visitado el 25/09/2014]. ELECTRthe Summer School.

Ámbito Jurídico.Com (2014): "Más de 30.000 demandas contra el Estado se presentaron en los cinco primeros meses del año". Disponible en: http:// www.ambitojuridico.com/BancoConocimiento/N/noti-142406-07mas_ de_30000_demandas_contra_el_estado/noti-142406-07mas_de_30000_demandas_contra_el_estado.asp?Miga=1.

\section{NORMAS JURÍDICAS CITADAS}

Decreto Ley № 01, por el cual se reforma el Código Contencioso Administrativo. Diario Oficial № 36.439, 10 de enero de 1984. 
Ley $N^{\circ} 1.437$, por la cual se expide el Código de Procedimiento Administrativo y de lo Contencioso Administrativo. Diario Oficial № 47.956, 18 de enero de 2011.

Ley $\mathrm{N}^{0} 1.448$, por la cual se dictan medidas de atención, asistencia y reparación integral a las víctimas del conflicto armado interno y se dictan otras disposiciones. Diario Oficial № 48.096, de 10 de junio de 2011.

Constitución Política. Gaceta Constitucional № 116, 20 de julio de 1991.

Ley $\mathrm{N}^{\circ} 446$, por la cual se adoptan como legislación permanente algunas normas del Decreto № 2.651 de 1991, se modifican algunas del Código de Procedimiento Civil, se derogan otras de la Ley No 23 de 1991 y del Decreto № 2.279 de 1989, se modifican y expiden normas del Código Contencioso Administrativo y se dictan otras disposiciones sobre descongestión, eficiencia y acceso a la justicia. Diario Oficial No 43.335, 8 de julio de 1998.

Ley $\mathrm{N}^{0} 1.564$, por medio de la cual se expide el Código General del Proceso y se dictan otras disposiciones. Diario Oficial № 48.489, 12 de julio de 2012.

Resolución E/CN.4/1998/53/Add.2. Organización de las Naciones Unidas (ONU). Consejo Económico y Social. Comisión de Derechos Humanos. Principios rectores de los desplazamientos internos, febrero 11 de 1998.

\section{JURISPRUDENCIA CITADA}

Sentencia T-025 de 2004, Corte Constitucional de Colombia, Sala Tercera de Revisión, M.P. Manuel José Cepeda Espinosa. Expediente: T-653010 y acumulados.

Resolución Caso Pueblo Indígena Kankuamo, Corte Interamericana de Derechos Humanos, Medidas provisionales solicitadas por la Comisión Interamericana de Derechos Humanos respecto de la República de Colombia.

Sentencia C-145 de 2009, Corte Constitucional de Colombia, Sala Plena, M.P. Nilson Pinilla Pinilla. Expediente: RE-137.

Auto suspensión provisional simple nulidad 1973-12 de 2013, Consejo de Estado de Colombia, M.P. Gustavo Eduardo Gómez Aranguren. Expediente: 11001-03-25-000-2012-00491-00 (1973-12).

Sentencia T-524 de 2005, Corte Constitucional de Colombia, Sala Séptima de Revisión, M.P. Humberto Antonio Sierra Porto. Expediente: no refiere.

Resolución Caso Comunidad Nonam del Pueblo Indígena Wounaan, Comisión Interamericana de Derechos Humanos, Medidas cautelares.

Resolución Caso Comunidad de Paz de San José de Apartadó, Corte Interamericana de Derechos Humanos, Medidas provisionales solicitadas por la Comisión Interamericana de Derechos Humanos respecto de Colombia. Resolución Caso Masacre de La Rochela, Corte Interamericana de Derechos Humanos, Medidas provisionales respecto de la República de Colombia. 
Sentencia T-786 de 2003, Corte Constitucional de Colombia, Sala Sexta de Revisión, M.P. Marco Gerardo Monroy Cabra. Expediente: T-731131.

Sentencia T-159 de 2011, Corte Constitucional de Colombia, Sala Octava de Revisión, M.P. Humberto Antonio Sierra Porto. Expediente: T-2858284.

Resolución Caso Comunidades de Juguamiendó y del Curvaradó, Corte Interamericana de Derechos Humanos, Medidas provisionales respecto de la República de Colombia.

Recurso Casación 4586, Tribunal Supremo de España. Sala de lo Contencioso Administrativo. Sección Tercera, M.P.: Eduardo Espín Templad. 